\title{
The influence of some correlates of blood pressure on its distribution in an Indian rural community
}

\author{
R. N. SRIVASTAVA, B. L. VERMA, ARUN KUMAR, AND J. P. SRIVASTAVA \\ From the Department of Social and Preventive Medicine, Maharani Laxmi Bai Medical College, Jhansi, India
}

SUMMARY A door-to-door investigation of casual blood pressure (BP) was carried out in 1325 adults in an Indian rural community to study its distribution and the influence on BP levels of some correlative factors-namely, age, sex, weight, build, and socioeconomic status. Systolic and diastolic levels of BP rose with increasing age, weight, and build. However, the socioeconomic status of respondents did not significantly influence their BP levels. After the age of 40, women had considerably higher levels of systolic blood pressure (SBP) than men. Evidence was found of multimodality, especially in diastolic blood pressure (DBP) distributions. The need is emphasised for an extensive investigation to obtain more accurate and generalised results, utilising the technique of blood pressure measurement recommended by the World Health Organisation (WHO, 1959).

The BP levels of individuals are thought to be associated with various personal, social, and environmental factors. A few of these factors have also been shown to be strongly correlated with BP-for example, age (Indrayan et al., 1972a; 1972b; Acheson, 1973; Srivastava et al., 1977a); sex (Gordon, 1964a; 1964b; Celine and Mathur, 1970); weight (Miall et al., 1968; Florey and Acheson, 1969; Srivastava et al., 1977b); build (Sive et al., 1970; Indrayan et al., 1972b); and social status (Gordon, 1967; Indrayan et al., 1972b; Labarthe et al., 1973). However, investigations carried out in different situations by different workers have in many respects shown different results, and some reports (Norman-Taylor and Rees, 1963; McKeown, 1964) are even controversial in regard to age.

\section{Material and methods}

Our investigation was carried out in the five villages of Kochha Bhanwar, Pichhore, Digara, Kargavan, and Mary, all lying within a radius of $8 \mathrm{~km}$ from the primary health centre at Kochha Bhanwar in Jhansi District, Utta Pradesh. The sampling frame consisted of persons aged 15 and over in these villages. The study sample should have included 2212 people but measurements of blood pressure, height, and weight were obtainable only for $1325(59.9 \%)$ and the rest $(40 \cdot 1 \%)$ did not respond. The majority of the sampled population were in low socioeconomic groups, and dependent mainly upon agriculture and manual labour for their livelihood. The reason why many respondents were not available at their homes was probably because of their daily travels to work on distant farms, etc. Also, intensive family planning campaigns to attain desired targets were being pursued with great vigour in the area during and before our investigation. In certain cases these campaigns resulted in compulsory sterilisation, and even some childless couples had to undergo vasectomy or tubectomy, so the fact that a significant proportion of respondents failed to co-operate was mainly because of their fear: they probably thought, mistakenly, that our investigating team were family planning personnel. The relatively high level of illiteracy in the area might also have contributed significantly to the lack of response.

The investigation was carried out during the period January to October 1972 between 9 am and 12 noon by a team of medical interns closely supervised by the authors. To minimise errors of measurement and to standardise blood pressure readings as far as possible, all interns were given a short training in the department a few days before the start of the inquiry. The salient guidelines outlined in the training session were as follows.

(i) Blood pressure to be recorded using mercury sphygmomanometers (with cuff sizes to cover at least two-thirds of the arm above the elbow) and this equipment to be checked daily before use for loss of mercury, dirt, oxidation in the tube, and any other defects that might have resulted in erroneous readings. 
(ii) The necessity of avoiding, as far as possible, being in a strained position when recording blood pressure.

(iii) Because random vertical arm displacement around the heart level increases the pressure consistently as the arm is lowered, respondents to be comfortably seated with the left arm slightly flexed and the whole forearm supported at heart level.

(iv) Systolic BP to be taken as the reading at which the sounds are first heard and diastolic BP that at which they disappear. If the sounds do not disappear, the point at which they become muffled to be taken as DBP (Acheson, 1973).

(v) Because single casual reading does not accurately characterise an individual's BP, three readings to be recorded, each one to the nearest $2 \mathrm{~mm} \mathrm{Hg}$, at intervals of about three to five minutes.

Blood pressure readings were taken at respondents' homes and the entire investigation was carried out as described above. Later, an average of three consecutive readings, recorded for each individual and for both pressures, was worked out and utilised throughout the analysis. Both systolic and diastolic levels were grouped into $10 \mathrm{~mm} \mathrm{Hg}$ intervals to avoid the effect of digit preference (Borhani et al., 1969). Despite the considerable limitations of casual blood pressure, only such pressure could be recorded for obvious reasons (Davies and Lewist, 1966).

Weight was recorded by weighing machine with the respondent standing on it without support and with minimal clothing. Height was measured with an anthropometer attached to a horizontal platform, the respondent standing erect with his back against a vertical measuring scale $5 \mathrm{~cm}$ wide, looking straight ahead with his head in the Frankfort horizontal plane. Build was measured with the help of Quetelet's index (Index $\left.=\frac{\text { Weight }}{\text { Height }^{2}} \times 100\right)$ which was worked out for each individual. Socioeconomic status was categorised into five classes on the basis of per caput monthly income, as suggested by Prasad (1968).

\section{Results}

Mean SBP and DBP by age, weight, build, and socioeconomic status for the two sexes are given in Tables 1, 2, 3, and 4 respectively. The trends are also shown graphically in Figs. 1, 2, 3, and 4. The degree of relationship between BP levels and these variables, worked out in terms of simple and partial correlation coefficients, is presented in Tables 5 and 6 respectively. Characteristics of percentage distributions of BP levels by sex in relation to the changing values of these variables were also studied; however, for the sake of brevity, the details are not given here. Analysis of the findings follows.

AGE

The findings indicate that SBP and DBP levels in both men and women increased with advancing age. However, the pattern was not the same in both sexes.

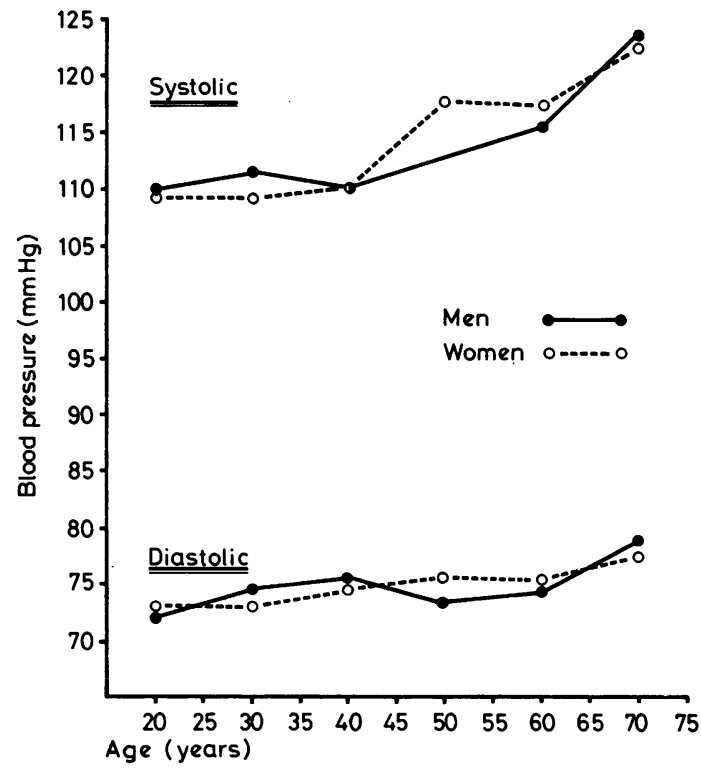

Fig. 1 Mean blood pressure levels by age and sex

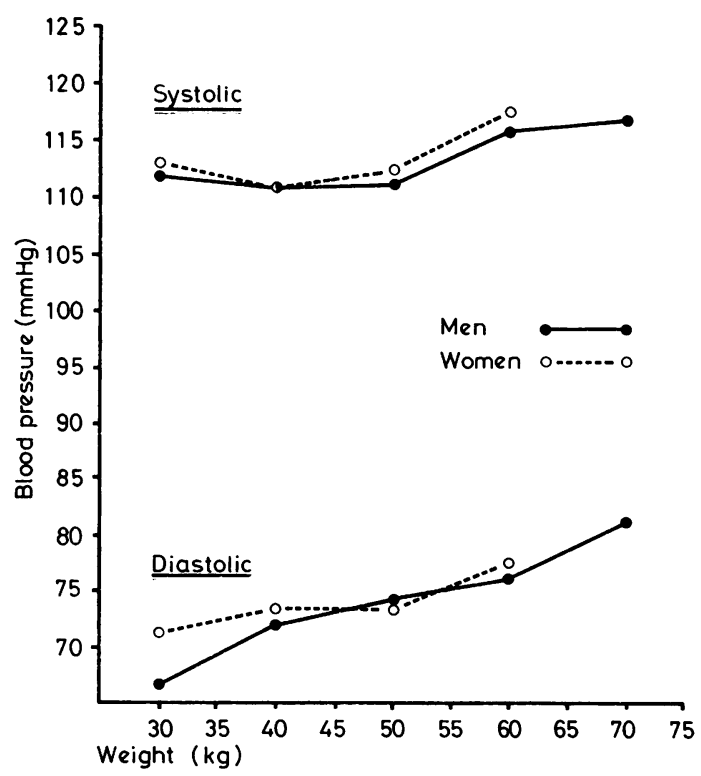

Fig. 2 Mean blood pressure levels by weight and sex. 
Table 1 Mean, standard deviation, and coefficient of variation (\%) of systolic and diastolic blood pressures by age and sex

\begin{tabular}{|c|c|c|c|c|c|c|c|c|c|c|c|c|}
\hline \multirow[b]{3}{*}{$\begin{array}{l}\text { Age group } \\
\text { (years) }\end{array}$} & \multicolumn{6}{|c|}{$M A L E$} & \multicolumn{6}{|c|}{$F E M A L E$} \\
\hline & \multirow[b]{2}{*}{ Frequency } & \multicolumn{2}{|l|}{ SYSTOLIC } & \multicolumn{3}{|c|}{ DIASTOLIC } & \multirow[b]{2}{*}{ Frequency } & \multicolumn{2}{|l|}{ SYSTOLIC } & \multicolumn{3}{|c|}{ DIASTOLIC } \\
\hline & & Mean $\pm S D$ & $\begin{array}{l}\text { Coefficient } \\
\text { of variation }\end{array}$ & Mean & $\pm S D$ & $\begin{array}{l}\text { Coefficient } \\
\text { of variation }\end{array}$ & & Mean $\pm S D$ & $\begin{array}{l}\text { Coefficient } \\
\text { of variation }\end{array}$ & Mean & $\pm S D$ & $\begin{array}{l}\text { Coefficient } \\
\text { of variation }\end{array}$ \\
\hline $\begin{array}{l}15-24 \\
25-34 \\
35-44 \\
45-54 \\
55-64 \\
65 \text { and over }\end{array}$ & $\begin{array}{r}154 \\
141 \\
149 \\
106 \\
60 \\
30\end{array}$ & $\begin{array}{l}109.9 \pm 11.0 \\
111.5 \pm 10.3 \\
109.9 \pm 10.4 \\
112.9 \pm 13.9 \\
114.8 \pm 16.3 \\
122.7 \pm 21.9\end{array}$ & $\begin{array}{r}10 \cdot 0 \\
9 \cdot 3 \\
9 \cdot 8 \\
12 \cdot 3 \\
14 \cdot 2 \\
17 \cdot 9\end{array}$ & $\begin{array}{l}71 \cdot 9 \\
73 \cdot 8 \\
74 \cdot 8 \\
73 \cdot 4 \\
74 \cdot 2 \\
78 \cdot 5\end{array}$ & $\begin{array}{l} \pm 9.1 \\
\pm 8.3 \\
\pm 8.5 \\
\pm 9.5 \\
\pm 9.1 \\
\pm 10.5\end{array}$ & $\begin{array}{l}12 \cdot 6 \\
11 \cdot 3 \\
11 \cdot 4 \\
12 \cdot 9 \\
12 \cdot 3 \\
13 \cdot 2\end{array}$ & \begin{tabular}{r|}
160 \\
173 \\
135 \\
114 \\
66 \\
37
\end{tabular} & $\begin{array}{l}109.5 \pm 11.2 \\
109.0 \pm 11.7 \\
110.1 \pm 12.7 \\
117.8 \pm 15.9 \\
117.4 \pm 16.7 \\
122.3 \pm 16.3\end{array}$ & $\begin{array}{l}10 \cdot 2 \\
10 \cdot 7 \\
11 \cdot 9 \\
13 \cdot 5 \\
14 \cdot 3 \\
13 \cdot 3\end{array}$ & $\begin{array}{l}72 \cdot 5 \\
73 \cdot 1 \\
73 \cdot 8 \\
75 \cdot 5 \\
75 \cdot 1 \\
76 \cdot 5\end{array}$ & $\begin{array}{r} \pm 8.2 \\
\pm 8.6 \\
\pm 9.0 \\
\pm 8.5 \\
\pm 8.6 \\
\pm 10.7\end{array}$ & $\begin{array}{l}11 \cdot 4 \\
11 \cdot 8 \\
12 \cdot 2 \\
11 \cdot 2 \\
11 \cdot 4 \\
13.9\end{array}$ \\
\hline
\end{tabular}

Table 2 Mean, standard deviation, and coefficient of variation (\%) of systolic and diastolic blood pressures by weight and sex

\begin{tabular}{|c|c|c|c|c|c|c|c|c|c|c|c|c|}
\hline \multirow[b]{3}{*}{$\begin{array}{l}\text { Weight } \\
(\boldsymbol{k g})\end{array}$} & \multicolumn{6}{|c|}{$M A L E$} & \multicolumn{6}{|c|}{$F E M A L E$} \\
\hline & \multirow[b]{2}{*}{ Frequency } & \multicolumn{2}{|l|}{ SYSTOLIC } & \multicolumn{3}{|c|}{ DIASTOLIC } & \multirow[b]{2}{*}{ Frequency } & \multicolumn{2}{|l|}{ SYSTOLIC } & \multicolumn{3}{|c|}{ DIASTOLIC } \\
\hline & & Mean $\pm S D$ & $\begin{array}{l}\text { Coefficient } \\
\text { of variation }\end{array}$ & Mean & $\pm S D$ & $\begin{array}{l}\text { Coefficient } \\
\text { of variation }\end{array}$ & & Mean $\pm S D$ & $\begin{array}{l}\text { Coefficient } \\
\text { of variation }\end{array}$ & Mean & $\pm S D$ & $\begin{array}{l}\text { Coefficient } \\
\text { of variation }\end{array}$ \\
\hline $\begin{array}{l}\text { Below } 35 \\
35-44 \\
45-54 \\
55-64 \\
65 \text { and over }\end{array}$ & $\begin{array}{r}10 \\
164 \\
348 \\
101 \\
17\end{array}$ & $\begin{array}{l}102.0 \pm 6.7 \\
110.8 \pm 14.7 \\
111.5 \pm 12.4 \\
115.8 \pm 11.5 \\
115.6 \pm 11.4\end{array}$ & $\begin{array}{r}6 \cdot 6 \\
13 \cdot 2 \\
11 \cdot 1 \\
10 \cdot 0 \\
9.9\end{array}$ & $\begin{array}{l}67 \cdot 0 \\
72 \cdot 3 \\
73 \cdot 9 \\
75 \cdot 9 \\
81 \cdot 0\end{array}$ & $\begin{array}{l} \pm 4.4 \\
\pm 9.4 \\
\pm 8.5 \\
\pm 8.8 \\
\pm 9.3\end{array}$ & $\begin{array}{r}6.5 \\
13.0 \\
11 \cdot 5 \\
11.6 \\
11 \cdot 5\end{array}$ & $\begin{array}{r}45 \\
410 \\
202 \\
28 \\
\end{array}$ & $\begin{array}{l}112.6 \pm 15.2 \\
111.3 \pm 13.5 \\
113.0 \pm 13.3 \\
118.9 \pm 17.3\end{array}$ & $\begin{array}{l}13 \cdot 6 \\
12 \cdot 1 \\
11 \cdot 8 \\
14 \cdot 5\end{array}$ & $\begin{array}{l}71 \cdot 1 \\
73 \cdot 4 \\
74 \cdot 6 \\
78 \cdot 2 \\
.\end{array}$ & $\begin{array}{r} \pm 7.6 \\
\pm 8.7 \\
\pm 8.4 \\
\pm 10.8\end{array}$ & $\begin{array}{l}10 \cdot 7 \\
11 \cdot 8 \\
11 \cdot 2 \\
13 \cdot 8\end{array}$ \\
\hline
\end{tabular}

- No female of weight $65 \mathrm{~kg}$ or more was observed.

Table 3 Mean, standard deviation, and coefficient of variation (\%) of systolic and diastolic blood pressures by build (index $\left.{ }^{*}=\frac{W}{H^{2}} \times 100\right)$ and sex

\begin{tabular}{|c|c|c|c|c|c|c|c|c|c|c|c|c|}
\hline \multirow[b]{3}{*}{$\begin{array}{l}\text { Build } \\
\text { (index) }\end{array}$} & \multicolumn{6}{|c|}{$M A L E$} & \multicolumn{6}{|c|}{$F E M A L E$} \\
\hline & \multirow[b]{2}{*}{ Frequency } & \multicolumn{2}{|l|}{ SYSTOLIC } & \multicolumn{3}{|c|}{ DIASTOLIC } & \multirow[b]{2}{*}{ Frequency } & \multicolumn{2}{|l|}{ SYSTOLIC } & \multicolumn{3}{|c|}{ DIASTOLIC } \\
\hline & & Mean $\pm S D$ & $\begin{array}{l}\text { Coefficient } \\
\text { of variation }\end{array}$ & Mean & $\pm S D$ & $\begin{array}{l}\text { Coefficient } \\
\text { of variation }\end{array}$ & & Mean $\pm S D$ & $\begin{array}{l}\text { Coefficient } \\
\text { of variation }\end{array}$ & Mean & $\pm S D$ & $\begin{array}{l}\text { Coefficient } \\
\text { of variation }\end{array}$ \\
\hline $\begin{array}{l}\quad<0.19 \\
0.19-0.21 \\
0.22-0.24 \\
0.25 \text { andover }\end{array}$ & $\begin{array}{r}229 \\
307 \\
89 \\
15\end{array}$ & $\begin{array}{l}109.8 \pm 13.3 \\
112.0 \pm 12.3 \\
116.5 \pm 13.5 \\
114.3 \pm 13.3\end{array}$ & $\begin{array}{l}12 \cdot 1 \\
11 \cdot 0 \\
11 \cdot 6 \\
11 \cdot 7\end{array}$ & $\begin{array}{l}72 \cdot 7 \\
73 \cdot 5 \\
76 \cdot 1 \\
82 \cdot 2\end{array}$ & $\begin{array}{l} \pm 8.9 \\
\pm 8.3 \\
\pm 10.0 \\
\pm \quad 9.1\end{array}$ & $\begin{array}{l}12 \cdot 2 \\
11 \cdot 3 \\
13 \cdot 1 \\
11 \cdot 1\end{array}$ & $\begin{array}{r}196 \\
339 \\
109 \\
41\end{array}$ & $\begin{array}{l}111.5 \pm 13.1 \\
110.9 \pm 13.6 \\
114.4 \pm 13.0 \\
118.7 \pm 18.7\end{array}$ & $\begin{array}{l}11 \cdot 7 \\
12 \cdot 2 \\
11 \cdot 4 \\
15 \cdot 7\end{array}$ & $\begin{array}{l}73 \cdot 3 \\
73 \cdot 1 \\
74 \cdot 9 \\
79 \cdot 2\end{array}$ & $\begin{array}{r} \pm 8.3 \\
\pm 8.4 \\
\pm 9.2 \\
\pm 10.6\end{array}$ & $\begin{array}{l}15 \cdot 1 \\
11 \cdot 5 \\
12 \cdot 2 \\
13 \cdot 4\end{array}$ \\
\hline
\end{tabular}

"Weight in $\mathrm{kg}$, height in $\mathrm{cm}$.

Table 4 Mean, standard deviation, and coefficient of variation (\%) of systolic and diastolic blood pressures by socioeconomic status and sex

\begin{tabular}{|c|c|c|c|c|c|c|c|c|c|c|c|c|}
\hline \multirow{3}{*}{$\begin{array}{l}\text { Social Class* } \\
\text { (per caput } \\
\text { monthly } \\
\text { income) }\end{array}$} & \multicolumn{6}{|c|}{$M A L E$} & \multicolumn{6}{|c|}{ FEMALE } \\
\hline & \multirow[b]{2}{*}{ Frequency } & \multicolumn{2}{|l|}{ SYSTOLIC } & \multicolumn{3}{|c|}{ DIASTOLIC } & \multirow[b]{2}{*}{ Frequency } & \multicolumn{2}{|l|}{ SYSTOLIC } & \multicolumn{3}{|c|}{ DIASTOLIC } \\
\hline & & Mean $\pm S D$ & $\begin{array}{l}\text { Coefficient } \\
\text { of variation }\end{array}$ & Mean & $\pm S D$ & $\begin{array}{l}\text { Coefficient } \\
\text { of variation }\end{array}$ & & Mean $\pm S D$ & $\begin{array}{l}\text { Coefficient } \\
\text { of variation }\end{array}$ & Mean & $\pm S D$ & $\begin{array}{l}\text { Coefficient } \\
\text { of variation }\end{array}$ \\
\hline $\begin{array}{l}\text { Social Class } \\
\text { III } \\
\text { (Rupees } \\
70-149 \text { ) }\end{array}$ & 19 & $116.6 \pm 13.4$ & $11 \cdot 5$ & $75 \cdot 1$ & \pm 7.5 & $10 \cdot 0$ & 19 & $116 \cdot 6 \pm 16 \cdot 1$ & $13 \cdot 8$ & $74 \cdot 6$ & $\pm 7 \cdot 5$ & $10 \cdot 1$ \\
\hline $\begin{array}{l}\text { Social Class } \\
\text { IV } \\
\text { (Rupees } \\
\text { 30-69) }\end{array}$ & 474 & $111 \cdot 7 \pm 12 \cdot 1$ & $10 \cdot 8$ & 73.9 & \pm 8.6 & $11 \cdot 6$ & 510 & $112.4 \pm 13.7$ & $12 \cdot 2$ & $74 \cdot 1$ & \pm 8.4 & $11 \cdot 4$ \\
\hline $\begin{array}{l}\text { Social Class } \\
\text { V } \\
\text { (below } \\
\text { Rupees 30) }\end{array}$ & 147 & $111.9 \pm 15 \cdot 3$ & $13 \cdot 7$ & $73 \cdot 0$ & \pm 9.3 & $12 \cdot 7$ & 156 & $111 \cdot 4 \pm 14 \cdot 2$ & $12 \cdot 8$ & $72 \cdot 6$ & \pm 9.6 & $13 \cdot 3$ \\
\hline
\end{tabular}

\footnotetext{
- No respondent came from Social Class I (Rupees 399 and above) and Social Class II (Rupees 150-299). £1.00 = approximately 17 Rupees.
} 
Furthermore, the quantum of increase was higher for SBP than for DBP and more specific after the age of 40. The relationship of SBP with age was stronger than that of DBP. In both males and females dispersion in SBP also increased with age.

Although significantly positive correlations with age of SBP and DBP levels (Table 5) clearly indicate a rise in blood pressure with advancing age, this relationship might also be suspected as being due to the influence of some associated factors, namely, weight and/or build, etc. The observed zero order correlations between blood pressure and age are low because of non-linear trends (Fig. 1). First order partial correlation coefficients between the two parameters, age and blood pressure, keeping weight and build constant, in turn, were worked out. In each case the correlations confirmed (Table 6) that there was a real relationship between BP levels and age and this was not due to the influence of weight or of build.

\section{SEX}

Mean SBP and DBP levels were $109.4 \pm 14.2$ and $72 \cdot 5 \pm 8 \cdot 1$ respectively in males and $111.9 \pm 13 \cdot 8$ and $72.7 \pm 9.1$ respectively in females. Mean DBP in the two sexes did not differ significantly $(Z=0.3153, P>0.70)$. However, mean SBP showed a highly significant difference $(Z=3.2574$ $P<0 \cdot 01)$. Fig. 1 shows that women had higher SBP levels than men only after the age of 40 .

\section{WEIGHT}

As with age, blood pressure also showed a tendency to increase with increasing weight. Systolic BP in both men and women tended to increase after about $40 \mathrm{~kg}$. However, women weighing $40 \mathrm{~kg}$ or less had higher DBP levels than men (Fig. 2). Percentage distributions of BP levels for different weight groups tended to shift towards the right, indicating raised BP levels in heavier persons. Significantly positive correlation coefficients also indicated that BP levels were higher in heavier persons.

Again, the significant correlations between BP levels and weight might be presumed to have been due to the effect of age. However, when this effect was eliminated from both weight and BP levels, the relationship between the two parameters in each case remained significantly positive, clearly indicating that the observed relationship was not due to the effect of age. However, build-independent correlations between the two parameters were not worked out because the build index used here has been defined so as to obtain the maximum possible dependency with weight.

B U I L D

As stated earlier, the build of respondents was categorised using Quetelet's index. Systolic and diastolic BP levels increased considerably with increasing bulkiness of build in both men and women. The quantum of this increase was, however, higher for persons with a build index higher than $0 \cdot 20$ (Fig. 3) except for SBP in males which declined after build index $0 \cdot 23$. A shift of the percentage distributions of BP levels for different build groups towards the right, and significantly positive correlations between BP levels and build, both corroborated the fact that bulkier persons had higher BP levels.

As with age and weight, first order correlation coefficients between BP levels and build, taking age as constant, were also calculated. Such correlations indicate that the observed significant relationship between the two parameters was real and not due to the effect of age (Table 6).

\section{SOCIOECONOMIC STATUS}

In the stratum studied, most people belonged to Social Classes IV and V and there were none from Social Classes I and II (Table 4). Those in Social Class III tended to have higher BP levels, particularly SBP, than those in Social Classes IV and V (Fig. 4). However, the results may not be significant because of the small number of observations in the former group. The low correlations of BP levels with social class (Table 5) are obvious because of non-linearity, especially as SBP levels in the other two social classes yielded a larger number of observations. Thus, the analyses reveal that a respondent's social status did not influence the BP levels of men or women in the community studied.

The percentage distributions of BP levels by changing values of different variables-age, weight, build, and social class-gave clear evidence on multimodality in BP distributions. This feature was observed for every subgroup of variables, so the biases are unlikely to have affected the comparisons between mean values of BP relating to age, weight, build, etc.

\section{Discussion}

The results show that all the factors considered except socioeconomic status had a bearing on the distribution of BP levels. However, the pattern of influence was not the same in each sex nor for both SBP and DBP.

A significantly positive relationship was observed of age with SBP and DBP for each sex. Such a tendency has also been found by many other workers (Florey and Acheson, 1969; Indrayan et al., 1972a; 1972b; Acheson, 1973; Srivastava et al., 1977a). The relatively higher increase in the dispersion of systolic BP and mean levels of both pressures in the two sexes after the age of 40 was probably due to the constant age influence. This also indicates that as age 
The influence of some correlates of blood pressure on its distribution in an Indian rural community

Table 5 Significance of some of the correlates of systolic and diastolic blood pressures in the two sexes

\begin{tabular}{|c|c|c|c|c|}
\hline \multirow[b]{3}{*}{$\begin{array}{l}\text { Correlates of } \\
\text { blood pressure }\end{array}$} & \multicolumn{2}{|c|}{$M A L E$} & \multicolumn{2}{|c|}{ FEMALE } \\
\hline & SYSTOLIC & DIASTOLIC & SYSTOLIC & DIASTOLIC \\
\hline & $\begin{array}{l}\text { Correlation } \\
\text { coefficient }\end{array}$ & $\begin{array}{l}\text { Correlation } \\
\text { coefficient }\end{array}$ & $\begin{array}{l}\text { Correlation } \\
\text { coefficient }\end{array}$ & $\begin{array}{l}\text { Correlation } \\
\text { coefficient }\end{array}$ \\
\hline Age & $0 \cdot 20^{* * *}$ & $0.13 * * *$ & $0 \cdot 27^{* * *}$ & $0.08^{*}$ \\
\hline Weight & $0 \cdot 16^{* * *}$ & $0 \cdot 19^{* * *}$ & $0.08^{*}$ & $0 \cdot 11^{* *}$ \\
\hline Build & $0 \cdot 16^{* * *}$ & $0 \cdot 18^{* * *}$ & $0 \cdot 12^{* *}$ & $0 \cdot 12^{* *}$ \\
\hline Socioeconomic status & 0.02 & -0.07 & -0.05 & -0.07 \\
\hline
\end{tabular}

*P<0.05 ** $\mathrm{P}<0.01 \quad$ *** $\mathrm{P}<0.001$

Table 6 Significance of some of the first order partial correlation coefficients between blood pressure levels and their correlates in the two sexes

\begin{tabular}{|c|c|c|c|c|}
\hline \multirow[b]{3}{*}{$\begin{array}{l}\text { Partial correlation } \\
\text { coefficient (rij.k)* }\end{array}$} & \multicolumn{2}{|c|}{ MALE } & \multicolumn{2}{|c|}{ FEMALE } \\
\hline & SYSTOLIC & DIASTOLIC & SYSTOLIC & DIASTOLIC \\
\hline & $\begin{array}{l}\text { Value of } \\
\text { rij.k }\end{array}$ & $\begin{array}{l}\text { Vlaue of } \\
\text { rij.k }\end{array}$ & $\begin{array}{l}\text { Value of } \\
\text { rij.k }\end{array}$ & $\begin{array}{l}\text { Value of } \\
\text { rij.k }\end{array}$ \\
\hline${ }^{r_{12.3}}$ & $0.21^{* * *}$ & $0 \cdot 15^{* * *}$ & $0 \cdot 29 * * *$ & $0 \cdot 10^{* * *}$ \\
\hline$r_{12.4}$ & $0 \cdot 20^{* * *}$ & $0 \cdot 14^{* * *}$ & $0 \cdot 30^{* * *}$ & $0 \cdot 10^{* *}$ \\
\hline$r_{13 \cdot 2}$ & $0 \cdot 18^{* * *}$ & $0 \cdot 20^{* * *}$ & $0 \cdot 12^{* * *}$ & $0 \cdot 13^{* * *}$ \\
\hline$r_{14 \cdot 2}$ & $0 \cdot 16^{* * *}$ & $0 \cdot 18^{* * *}$ & $0 \cdot 17^{* * *}$ & $0 \cdot 14^{* * *}$ \\
\hline
\end{tabular}

* $x_{1}=$ BP level $\quad x_{2}=$ age $\quad x_{3}=$ weight $\quad x_{4}=$ build

*P<0.05 *P $\mathrm{P}<0.01 \quad$ ***P $\mathrm{P}<0.001$

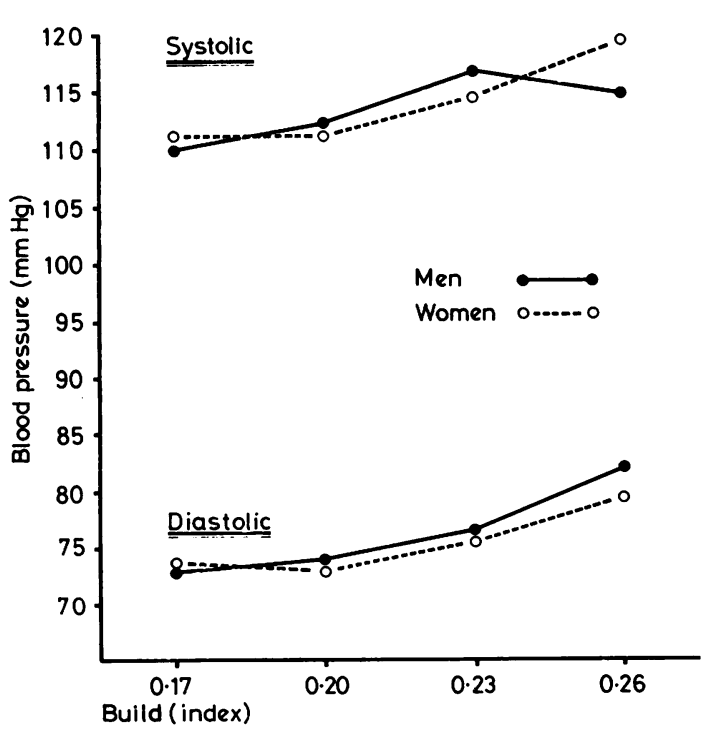

Fig. 3 Mean blood pressure levels by build and sex.

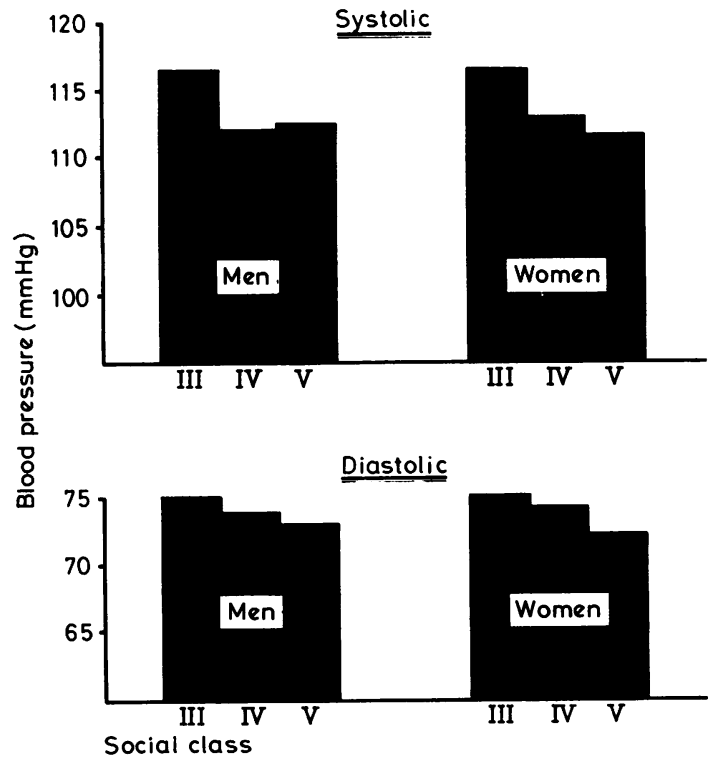

Fig. 4 Mean blood pressure levels by socioeconomic status and sex. 
advanced, variability in SBP tended to become higher in both sexes. Evidence showing a relatively stronger relationship between age and blood pressure in older persons than in younger ones was available (Boe et al., 1957; Acheson, 1973; Srivastava et al., 1977a).

Sex was also shown to have a considerable impact on the distribution of SBP levels. This corroborated the findings of some earlier authors (Celine and Mathur, 1970; Indrayan et al., 1972b; Acheson, 1973; Beaglehole et al., 1975) that BP generally differs in the two sexes. Indrayan et al., (1972a) observed somewhat higher levels in males than females in an urban Indian population. In the present study, significantly higher SBP levels were observed in females than in males after the age of 40 and no significant sex differences were noted for DBP. This observed disparity is probably due to the dissimilar nature of the population in the two studies.

In a study of adults in the United States of America (Gordon, 1964), almost similar sex differences were noted. However, SBP levels and their rate of increase in relation to age for both men and women were considerably higher than those observed in the present study. These different findings are perhaps due to psychosocial, cultural, and environmental differences in the two populations.

Significantly positive correlations of BP levels with weight, and the shifting of distributions towards the right with increasing weight in both sexes, indicated a definite rise in blood pressure with increasing weight. Furthermore, age-independent significant correlation coefficients between weight and BP levels (Table 6) clearly showed that the relationship between the two parameters was real and not due to the influence of age. Since the build index of Quetelet used in this study is by definition a function of weight and therefore yields strong correlation with weight (Verma et al., 1979), the relationship between the two parameters weight and blood pressure, eliminating from both the effect of build, was not investigated. Other studies have also established a positive bearing of weight on blood pressure levels (Harlan et al., 1962; Miall et al., 1968; Florey and Acheson, 1969; Srivastava et al., 1977b).

A general tendency of blood pressure to increase with increasing bulkiness of build in both men and women has been observed in other studies (Florey and Acheson, 1969; Sive et al., 1970; Indrayan et al., $1972 b ; 1974)$ and was also noticed in the present inquiry. But although quantitatively higher BP levels in the later build groups (Table 3 ) clearly reveal raised blood pressure with increasing bulk, some contribution to these raised levels might also have been due to the effect of overestimation of blood pressure in obese arms (Miall et al., 1968).
A clear picture of the influence of socioeconomic status on blood pressure cannot be delineated in this study because of the absence of respondents in Social Classes I and II. However, statistically insignificant correlation coefficients between socioeconomic status and BP levels in the two sexes are an indication of the negligible effect.

In spite of the fact that the effect of digit preference was eliminated from the data as far as possible, the bimodality as well as the multimodality in the BP distributions, especially those for DBP, were frequently observed. Such evidence has been reported by other workers (Morrison and Morris, 1959; Platt, 1959; Lowe and McKeown, 1962). In the present study, as shown by Lowe and McKeown, such characteristics could be observed probably because of some extraneous factors such as the small number of persons studied and/or the pooling of data recorded by different observers during the investigation. However, since the multimodality was observed for every subgroup of variables, comparisons between mean values of BP in relation to various factors would remain almost unaffected by the biases incurred.

Although our study provides important information on salient features of BP distribution in a rural adult population in relation to the various factors, it also suffers from some limitations. The data were obtained from a cross-sectional survey, and may have deficiencies of the kind common to such studies. Another limitation is due to the casual nature of blood pressures studied. A field investigation in randomly selected persons using the World Health Organisation's recommended criteria for blood pressure measurements (World Health Organisation, 1959) may provide more accurate and generalised results.

We thank Sri R. S. Chauhan, health educator in the Department of Social and Preventive Medicine, Maharani Laxmi Bai Medical College, and the teams of interns posted to the Department.

Reprints from R. N. Srivastava, Department of Social and Preventive Medicine, Maharani Laxmi Bai Medical College, Jhansi, Uttar Pradesh, India.

\section{References}

Acheson, R. M. (1973). Blood pressure in a national sample of US adults: Percentile distribution by age, sex and race. International Journal of Epidemiology, 2, 293-301.

Beaglehole, R., Salmond, C. E., and Prior, I. A. M. (1975). A family study of blood pressure in Polynesians. International Journal of Epidemiology, 4, 217-220. 
Boe, J., Humerfelt, S., and Wederveng, F. (1957). The blood pressure in population, blood pressure readings and height and weight determination in the adult population of the city of Bergen. Acta Medica Scandinavica, Supplement No. 321, 15-336.

Borhani, N. O., Slansky, O., Graffey W., and Borkman, T. (1969). Familial aggregation of blood pressure. American Journal of Epidemiology, 89, 537-546.

Celine, V. J., and Mathur, B. B. L. (1970). Blood pressure variations in ageing: a study in the central Indian population.Journal of the Indian Medical Association, 55, 129-130.

Davies, T. W., and Lewist, H. E. (1966). Simple method of field studies of human blood pressure. Journal of Physiology, 188, 7-10.

Florey, C. du V., and Acheson, R. M. (1969). Blood pressure as it relates to physique, blood glucose and serum cholesterol: United States 1960-1962. Monographs of US National Center for Health Statistics, Series 11, No. 34, pp. 1-26. US Department of Health, Education and Welfare: Washington DC.

Gordon, T. (1964a). Blood pressure of adults by age and sex: United States 1960-1962. Monographs of US National Center for Health Statistics, Series 11, No. 4, pp. 1-16. US Department of Health, Education and Welfare: Washington DC.

Gordon, T. (1964b). Blood pressure of adults by race and area: United States 1960-1962. Monographs of US National Center for Health Statistics, Series 11, No. 5, pp. 1-8. US Department of Health, Education and Welfare, Washington DC.

Gordon, T. (1967). Discussion on socio-economic factors in the epidemiology of hypertensive disease. In Epidemiology of Hypertension, p. 316. Edited by J. Stamler, R. Stamler, and T. N. Pullman. Grune and Stratton: New York.

Harlan, W. R., Osborne, R. K., and Grabiel, A. (1962). A longitudinal study of blood pressure. Circulation, 26, $530-543$.

Indrayan, A., Srivastava, R. N., and Bagchi, S. C. (1972a). Age regression of blood pressure in an urban population of age 15-59 years. Indian Journal of Medical Research, 60, 966-972.

Indrayan, A., Srivastava, R. N., and Bagchi, S. C. (1972b). Influence of some correlates of blood pressure on its distribution in an adult urban population of Allahabad. Indian Journal of Medical Research, 60, 651-660.
Indrayan, A., Kumar, A., Srivastava, R. N., and Bagchi, S. C. (1974). Multifactorial analysis of blood pressure levels in Allahabad urban community. Indian Journal of Public Health, 18, 1-7.

Labarthe, D., Reed, D., Brody, J., and Stallones, R. (1973). Health effects of modernization in Palau. American Journal of Epidemiology, 98, 161-174.

Lowe, C. R., and McKeown, T. (1962). Some sources of irregularity in the distribution of arterial pressure. In Epidemiology, pp. 131-141. Edited by J. Pamberton. Oxford University Press: London.

McKeown, T. (1964). Population study of arterial pressure. American Heart Journal, 67, 569-571.

Miall, W. E., Bell, R. A., and Lovell, H. G. (1968). Relation between change in blood pressure and weight. British Journal of Preventive and Social Medicine, 22, 73-80.

Morrison, S. L., and Morris, J. N. (1959). Epidemiological observations on high blood pressure without evident cause. Lancet, 2, 864-870.

Norman-Taylor, W., and Rees, W. H. (1963). Blood pressure in three new Hebrides communities. British Journal of Preventive and Social Medicine, 17, 141-144.

Platt, R. (1959). The nature of essential hypertension. Lancet, 2, 55-57.

Prasad, B. G. (1968). Social classification. Journal of the Indian Medical Association, 51, 365-366.

Sive, P. H., Medallie, J. H., Kahn, H. A., Naufeld, H. N., and Riss, E. (1970). Correlation of weight-height index with diastolic and with systolic blood pressure. British Journal of Preventive and Social Medicine, 24, 201-204.

Srivastava, R. N., Verma, B. L., Kumar, A., and Srivastava, J. P. (1977a). Blood pressure in a rural adult population: percentile distribution by age and sex. Indian Journal of Medical Research, 65, 142-149.

Srivastava, R. N., Verma, B. L. and Srivastava, J. P. (1977b). Influence of body-weight on blood pressure in an adult rural population. Annals of the National Academy of Medical Sciences (India), 13, 1-15.

Verma, B. L., Kumar, A., and Srivastava, R. N. (1979). Measurement of body build based on weight and height. An index for adults in an Indian population. Indian Journal of Public Health (In press).

World Health Organisation (1959). Hypertension and coronary heart disease-classification and criteria for epidemiological studies. Technical Report Series No. 168, 3-24. WHO: Geneva. 